\title{
Magnetic Field-Induced Solvothermal Synthesis of One-Dimensional Assemblies of Ni-Co Alloy Microstructures
}

\author{
Ming Jun Hu, Bin Lin, and Shu Hong Yu ( $\varangle)$ \\ Division of Nanomaterials \& Chemistry, Hefei National Laboratory for Physical Sciences at Microscale, School of Chemistry and \\ Materials, University of Science and Technology of China, Hefei 230026, China \\ Received: 31 July 2008/Accepted: 25 August 2008 \\ CTsinghua Press and Springer-Verlag 2008. This article is published with open access at Springerlink.com
}

\begin{abstract}
One-dimensional magnetic Ni-Co alloy microwires with different microstructures and differently shaped building blocks including spherical particles, multilayer stacked alloy plates, and alloy flowers, have been synthesized by an external magnetic field-assisted solvothermal reaction of mixtures of cobalt(II) chloride and nickel(II) chloride in 1, 2-propanediol with different $\mathrm{NaOH}$ concentrations. By adjusting the experimental parameters, such as precursor concentration and $\mathrm{Ni} / \mathrm{Co}$ ratio, $\mathrm{Ni}-\mathrm{Co}$ alloy chains with uniform diameters in the range $500 \mathrm{~nm}$ to $1.3 \mu \mathrm{m}$ and lengths ranging from several micrometers to hundreds of micrometers can be obtained. A mechanism of formation of the one-dimensional assemblies of magnetic $\mathrm{Ni}$-Co microparticles in a weak external magnetic field is proposed.
\end{abstract}

\section{KEYWORDS}

$\mathrm{Ni}$-Co alloy microstructures, magnetic field-induced assembly, solvothermal synthesis

\section{Introduction}

In the past decades, transition metal nanostructures, especially those of $\mathrm{Fe}, \mathrm{Co}$, and $\mathrm{Ni}$, have attracted considerable attention from scientists and engineers owing to their unique optical [1], magnetic [2], electrical [3], and catalytic properties [4] and their extensive technological applications $[2,5,6]$. As one important class of transition metal alloys, $\mathrm{Ni}-\mathrm{Co}$ alloys have high mechanical strength [7], good wear resistance [8], anticorrosive performance [9], thermal conductivity [10], thermal stability [11], electrical conductivity, electrocatalytic activity $[12,13]$, and specific magnetic properties $[14,15]$, indicating that $\mathrm{Ni}-\mathrm{Co}$ alloys should be good high-temperature catalysts and specific magnetic materials, and that they can be applied in some high-temperature electrochemical devices, such as solid oxide fuel cells (SOFCs) [16] and some electromagnetic devices, such as magnetic recording devices, ferrofluid dynamotors, and magcards $[17,18]$.

Micro- and nanoscale $\mathrm{Ni}-\mathrm{Co}$ alloy structures have been prepared by many methods, including electrochemical reduction $[19,20]$, mechanical alloying [21], leaching techniques [22], sol-gel routes [23], thermal decomposition of organometallic precursors [24], polyol reduction [25, 26], and reduction of metal salts by other strong reducing agents [27, 28]. Recently, several groups have reported the synthesis of one-dimensional $\mathrm{Ni}-\mathrm{Co}$

Address correspondence to shyu@ustc.edu.cn 
nanomaterials. For example, $\mathrm{Ni}-\mathrm{Co}$ alloy nanowire arrays were prepared by co-electrodepositing $\mathrm{Co}(\mathrm{II})$ and $\mathrm{Ni}(\mathrm{II})$ into the pores of porous anodic aluminum oxide templates [29], Ni-Co needle-like alloys were synthesized in water-in-oil microemulsions [30], hexagonal $\mathrm{Ni}-\mathrm{Co}$ nanowires were synthesized by heterogeneous nucleation in liquid polyols [25, 26] and chain-like Ni-Co alloys were synthesized by reduction of $\mathrm{Co}(\mathrm{II})$ and $\mathrm{Ni}(\mathrm{II})$ using hydrazine hydrate with the assistance of a surfactant [28]. However, all the above-mentioned synthetic methods require the use of either hard templates or surfactants or involve multiple steps.

An external magnetic field has been found to be an important tool for controlling the synthesis and assembly of magnetic materials. In recent years, a few groups have employed magnetic fields to assemble magnetic materials in order to obtain onedimensional nanostructures. For example, nickel wires and $\mathrm{Fe}_{3} \mathrm{O}_{4}$ nanowires have been synthesized under the influence of magnetic fields [31-33], phase-selective synthesis of ferrosulfide microrods has been realized by a hydrothermal process using an amino acid additive under the influence of an external magnetic field [34], Wang et al. synthesized necklace-like noble metal hollow nanoparticle chains by using necklace-like Co nanoparticle chains, previously synthesized in a magnetic field-induced process, as a sacrificial template [35], and Gu et al. demonstrated the alternating current magnetic fieldinduced assembly of magnetite nanoparticles and its close relationship with the surface charge [36]. In addition, magnetic fields have also been used to direct the alignment of vanadium pentoxide ribbons [37], mouse osteoblast cells [38], carbon nanotubes [39], and polystyrene nanoparticles in an aluminum ferrite layered block [40]. Recently, our group has reported that $\mathrm{Ni}-\mathrm{Co}$ nanochains and magnetic flux-closure nanorings can be prepared directly in high yield in triethylene glycol solution containing polyvinylpyrrolidone (PVP) [41].

To the best of our knowledge, magnetic fieldinduced synthesis of one-dimensional $\mathrm{Ni}-\mathrm{Co}$ alloy microstructures with control over the shape of the building blocks has not been reported to date. Moreover, little attention has been paid to the effect of varying the precursor concentration on the length of alloy chains in the presence of a constant magnetic field.

In this paper, we demonstrate a magnetic fieldguided solvothermal synthesis of one-dimensional magnetic $\mathrm{Ni}-\mathrm{Co}$ alloy microwires with different microstructures and differently shaped building blocks using mixtures of cobalt(II) chloride and nickel(II) chloride in 1, 2-propanediol with different $\mathrm{NaOH}$ concentrations. A possible mechanism of formation of the one-dimensional assemblies of magnetic $\mathrm{Ni}-\mathrm{Co}$ microwires under the influence of the weak external magnetic field has been proposed.

\section{Experimental}

$\mathrm{NiCl}_{2} \cdot 6 \mathrm{H}_{2} \mathrm{O}, \mathrm{CoCl}_{2} \cdot 6 \mathrm{H}_{2} \mathrm{O}, \mathrm{NaOH}$, hexamethylenetetramine (HMT), PVP, cetyltrimethylammonium bromide (CTAB), sodium oleate (SOA), dodecylbenzene sulfonic acid sodium salt (DBS), 1, 2-propanediol, and ethanol were purchased from the Shanghai Reagent Company (China). All reagents were of analytical grade and were used without further purification.

\subsection{Synthesis of $\mathrm{Ni}_{x} \mathrm{Co}_{1-x}$ alloys with different morphologies}

In a typical synthesis of $\mathrm{Ni}_{0.5} \mathrm{Co}_{0.5}$ alloy, $\mathrm{NiCl}_{2} \cdot 6 \mathrm{H}_{2} \mathrm{O}$ $(0.3 \mathrm{mmol}), \mathrm{CoCl}_{2} \cdot 6 \mathrm{H}_{2} \mathrm{O}(0.3 \mathrm{mmol})$, and hexamethylenetetramine $(0.9 \mathrm{mmol})$ were added to 1, 2-propanediol $(30 \mathrm{~mL})$ and heated for $10 \mathrm{~min}$ at $120{ }^{\circ} \mathrm{C}$, and then a certain amount of sodium hydroxide was added and the mixture heated at this temperature until a homogeneous solution was obtained. The solution was transferred to a $50 \mathrm{~mL}$ Teflon-lined stainless steel autoclave. The autoclave was sealed and maintained at $170{ }^{\circ} \mathrm{C}$ for $20 \mathrm{~h}$.

\subsection{Synthesis of one-dimensional $\mathrm{Ni}_{x} \mathrm{Co}_{1-x}$ alloy structures}

One-dimensional $\mathrm{Ni}_{x} \mathrm{Co}_{1-x}$ alloy structures were synthesized under the above conditions in the presence of a $0.08 \mathrm{~T}$ external magnetic field. After the solution was cooled to room temperature, the resulting black solid products were separated by means of their attraction to an external magnet, 
and then washed three times with distilled water and absolute ethanol. The product was dried under vacuum at $60^{\circ} \mathrm{C}$ for $4 \mathrm{~h}$.

\subsection{Characterization}

X-ray diffraction (XRD) patterns were recorded on a Philips $\mathrm{X}^{\prime}$ pert diffractometer with $\mathrm{Cu} \mathrm{K} \alpha$ radiation ( $\lambda=1.54178 \AA$ ). The morphology and structure of the samples were studied by field emission scanning electron microscopy (FE-SEM, JEOL JSM-6300F) and transmission electron microscopy (TEM, Hitachi, $\mathrm{H}-800$ ) with an accelerating voltage of $200 \mathrm{kV}$. High-resolution transmission electron microscope (HRTEM) photos and selected area electron diffraction (SAED) patterns were obtained on a JEOL-2010 transmission electron microscope. Local energy-dispersive X-ray spectrum (EDS) analysis was performed using an Oxford INCA system with the smallest analysis spot of $10 \mathrm{~nm}$.

\section{Results and discussion}

\subsection{Structure and morphology of $\mathrm{Ni}-\mathrm{Co}$ alloy} microstructures synthesized in the absence of a magnetic field

Different $\mathrm{Ni}_{x} \mathrm{Co}_{1-x}$ alloy microstructures were synthesized at an elevated temperature in 1, 2propanediol solution containing varying amounts of $\mathrm{NaOH}$. In these reactions, the 1, 2-propanediol acts as both the solvent and the reducing agent.

When the concentration of $\mathrm{NaOH}$ was $0.1 \mathrm{~mol} / \mathrm{L}$, cubic $\mathrm{Ni}_{x} \mathrm{Co}_{1-x}$ alloy microparticles were obtained. Figure 1 shows XRD patterns of the microparticle powders with different compositions. The peaks can be indexed to four planes $\langle 111\rangle,\langle 200\rangle,\langle 220\rangle$, and $\langle 311\rangle$ of an fcc phase. No other impurity peaks can be observed. The XRD patterns are very similar to those of both $\mathrm{Co}$ and $\mathrm{Ni}$, although slight variations in peak positions can be observed. In particular, the (200) peak always lies between the positions of the (200) peaks for pure $\mathrm{Ni}$ and pure $\mathrm{Co}$, and moves towards the position of the Co (200) peak with increasing Co content. The lattice constants of the materials increase with increasing Co content, with the values for $\mathrm{Ni}_{0.8} \mathrm{Co}_{0.2}, \mathrm{Ni}_{0.5} \mathrm{Co}_{0.5}$, and $\mathrm{Ni}_{0.2} \mathrm{Co}_{0.8}$ being $3.518 \AA$,

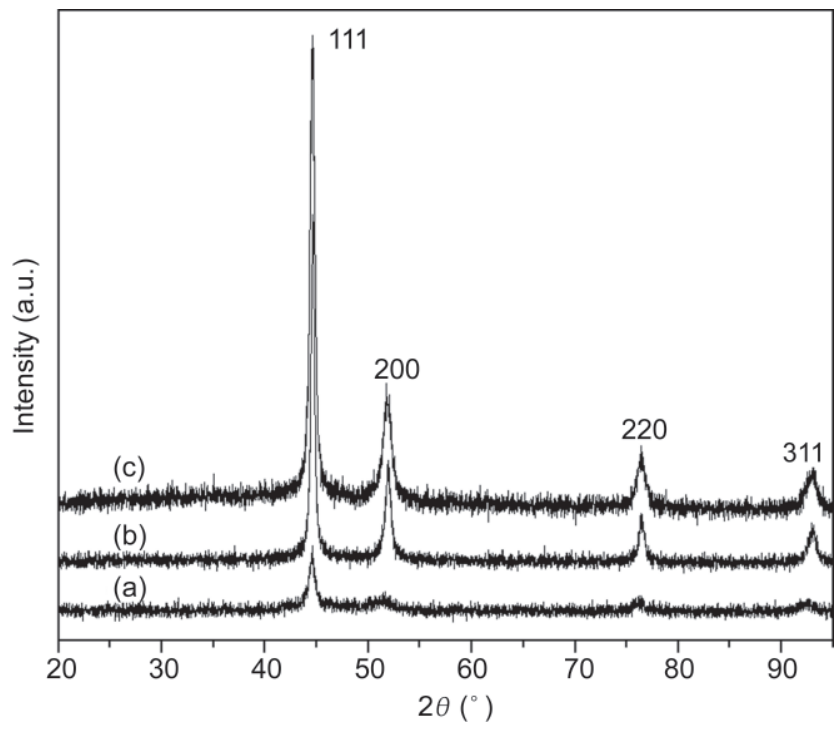

Figure 1 XRD patterns of $\mathrm{Co}_{x} \mathrm{Ni}_{1-x}$ powders prepared at $170{ }^{\circ} \mathrm{C}$ for $20 \mathrm{~h}$ by reduction in 1,2-propanediol with different molar ratios of $\mathrm{Ni} / \mathrm{Co}$ : (a) 1:4; (b) 1:1; (c) 4:1. [NaOH] $=0.1 \mathrm{~mol} / \mathrm{L}$

$3.520 \AA$, and $3.529 \AA$, respectively. These results are consistent with the formation of alloys of nickel and cobalt $[24,27,30,42]$.

An HRTEM image (Fig. 2(b)) of the edge of the particle shown in Fig. 2(a) reveals that the fringes have a lattice spacing of $2.05 \AA$, which corresponds to the $\{11 \overline{1}\}$ interplanar distance in $\mathrm{Ni}-\mathrm{Co}$ fcc solid solution alloys. The SAED pattern of $\mathrm{Ni}_{0.5} \mathrm{Co}_{0.5}$ shows that some isolated particles are single crystalline in nature (Fig. 2(c)). The diffraction pattern in Fig. 2(c) can be indexed as the [001] zone axis of the fcc structure, with a calculated lattice constant of $3.51 \AA$.

Energy dispersive X-ray spectroscopy (EDS) was performed on different particles. Figure 2(d) shows a representative EDS spectrum of the central part of a $\mathrm{Ni}_{0.5} \mathrm{Co}_{0.5}$ particle. The Ni/Co molar ratios obtained from the spectra were found to be almost constant, with a mean value of 51:49 (Fig. 2d). EDS analysis was also performed on alloy particles with different $\mathrm{Ni}$-Co compositions, such as $\mathrm{Ni}_{0.8} \mathrm{Co}_{0.2}$ and $\mathrm{Ni}_{0.2} \mathrm{Co}_{0.8}$. The mean $\mathrm{Ni} / \mathrm{Co}$ molar ratios in the alloy products were found to be very close to the molar ratios of the corresponding precursors, namely $\mathrm{Ni}_{0.81} \mathrm{Co}_{0.19}$ and $\mathrm{Ni}_{0.15} \mathrm{Co}_{0.85}$ (see Figs. S-1, S-2, S-3, Tables S-1, S-2, S-3 in the Electronic Supplementary Material (ESM)).

From Fig. 3, it can be seen that varying the reaction temperature has no marked effect on the

\section{圈国 Springer}




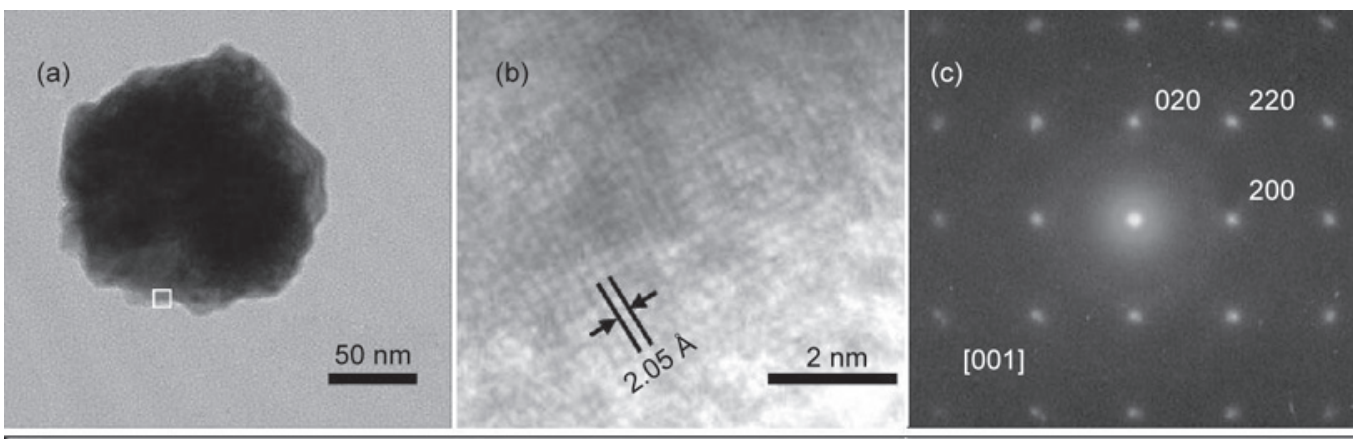

(d)

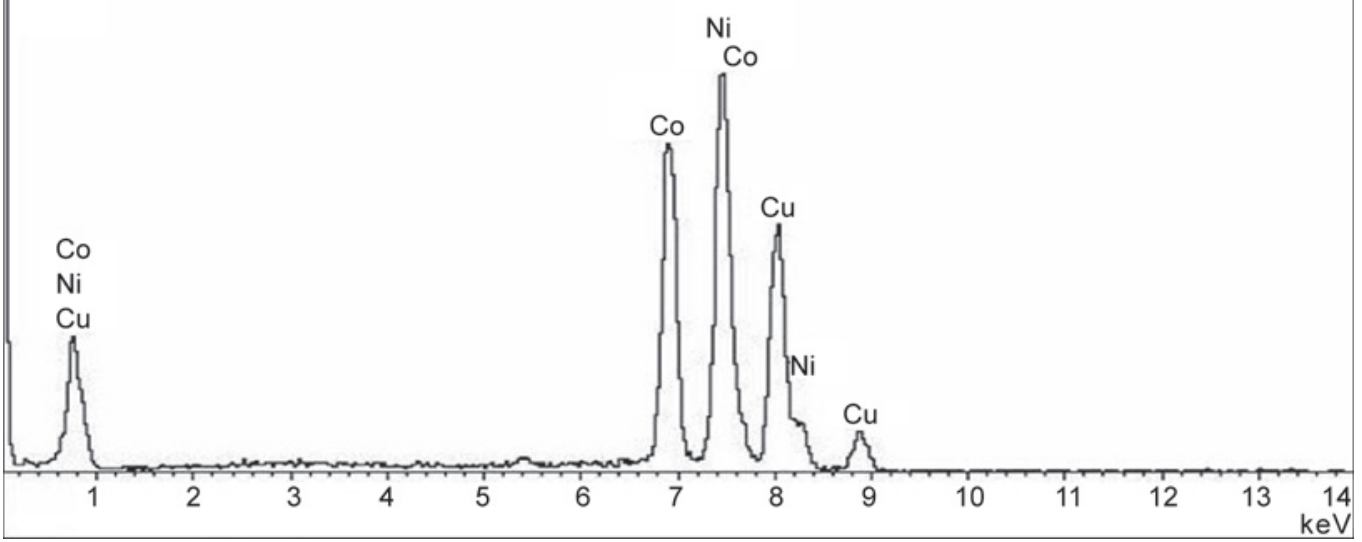

Figure 2 (a) TEM image of a single $\mathrm{Ni}_{0.5} \mathrm{CO}_{0.5}$ particle with a comparatively small size; (b) HRTEM of the area enclosed by the white box in (a); (c) selected area electron diffraction pattern of a selected particle; (d) energydispersive X-ray spectrum (EDS) of the central part of an $\mathrm{Ni}_{0.5} \mathrm{CO}_{0.5}$ particle

average particle size but the degree of uniformity of the particles was found to depend strongly on the temperature. At different reaction temperatures, the average particle size was always about $1 \mu \mathrm{m}$. The size distribution of the particles obtained at $160{ }^{\circ} \mathrm{C}$ was broad and in the range $200 \mathrm{~nm}$ to $1.3 \mu \mathrm{m}$ (Fig. 3(a)). Relatively uniform particles with a size of $900 \mathrm{~nm}$ $( \pm 50 \mathrm{~nm})$ were obtained at $170{ }^{\circ} \mathrm{C}$ (Fig. 3(b)). A further increase in temperature to $180{ }^{\circ} \mathrm{C}$, led to the particles becoming non-uniform again with their sizes ranging from $200 \mathrm{~nm}$ to $1.1 \mu \mathrm{m}$ as shown in Fig. 3(c). Reduction of the metal ions becomes difficult at reaction temperatures below $160{ }^{\circ} \mathrm{C}$. For example, $\mathrm{Ni}_{x} \mathrm{Co}_{1-x}$ particles were obtained in low yield at $150^{\circ} \mathrm{C}$. When the temperature was further lowered to $140{ }^{\circ} \mathrm{C}$, $\mathrm{Ni}(\mathrm{II})$ or $\mathrm{Co}(\mathrm{II})$ cannot be reduced at all. Based on these experiments, the optimal temperature to obtain uniform alloy particles is $170^{\circ} \mathrm{C}$.

It was found that $\mathrm{Co}(\mathrm{II})$ ions alone were only reduced with difficulty at $170{ }^{\circ} \mathrm{C}$ in 1,2-propanediol with an $\mathrm{NaOH}$ concentration of $0.1 \mathrm{~mol} / \mathrm{L}$, but that reduction of $\mathrm{Ni}(\mathrm{II})$ alone occurred readily under the same conditions. Thus, the reduction of $\mathrm{Co}$ (II) is clearly enhanced in the presence of nickel. This could be due to cathodic polarization of the $\mathrm{Ni}$ particles by electron transfer from radicals and the subsequent reduction of $\mathrm{Co}$ (II) directly on the surface of Ni particles. Henglein et al. reported a similar phenomenon in their synthesis of tin-gold alloy particles [43], as did Jiang et al. in their synthesis of copper-silver alloy nanoparticles [44]. Since the differences in oxidation-reduction potentials between $\mathrm{Ni}(\mathrm{II})$ and $\mathrm{Co}$ (II) in basic solution are smaller than those between $\mathrm{Sn}(\mathrm{II})$ and $\mathrm{Au}(\mathrm{III})$, or $\mathrm{Cu}(\mathrm{II})$ and $\mathrm{Ag}(\mathrm{I})$, it is reasonable to assume that when $\mathrm{Ni}$ (II) is reduced by polyol, electron transfer in solution will induce the simultaneous reduction of $\mathrm{Co}$ (II), leading to the formation of an alloy phase.

Although the effect of varying the reaction time on the shape of particles is not very marked as long 

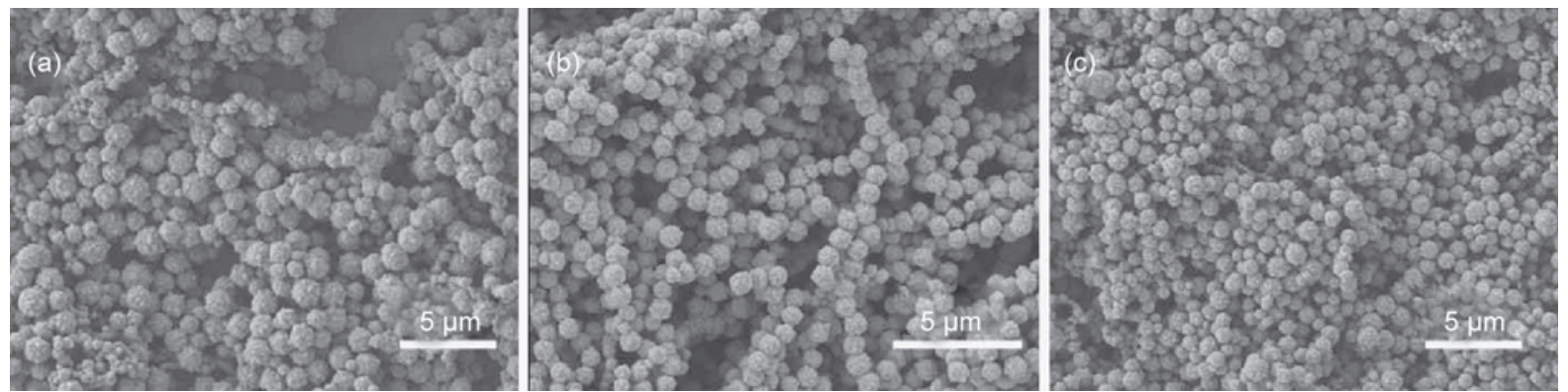

Figure $3 \mathrm{SEM}$ images of $\mathrm{Ni}_{0.5} \mathrm{Co}_{0.5}$ particles synthesized in polyol at different temperatures: (a) $160{ }^{\circ} \mathrm{C}$; (b) $170{ }^{\circ} \mathrm{C}$; (c) $180^{\circ} \mathrm{C}$. [ $\left.\mathrm{NaOH}\right]$ $=0.1 \mathrm{~mol} / \mathrm{L}$

as it exceeds $4 \mathrm{~h}$, longer reaction times favor the formation of more uniform alloy particles. Generally, in our experiments, the reaction time was set to $16^{-20} \mathrm{~h}$, so as to prepare uniform alloy particles (see Fig. S-4 in the Electronic Supplementary Material (ESM)).

The addition of limited amounts of HMT can improve the monodispersity of particles, but the concentration was always kept under $0.09 \mathrm{~mol} / \mathrm{L}$, and about 1.5 times of that of metal precursors. At higher concentrations of HMT, the separation of the products from solution is difficult as a large amount of organic flocculation appeared in the polyol solution. Different $\mathrm{Ni}^{2+}$ and $\mathrm{Co}^{2+}$ sources were also used to
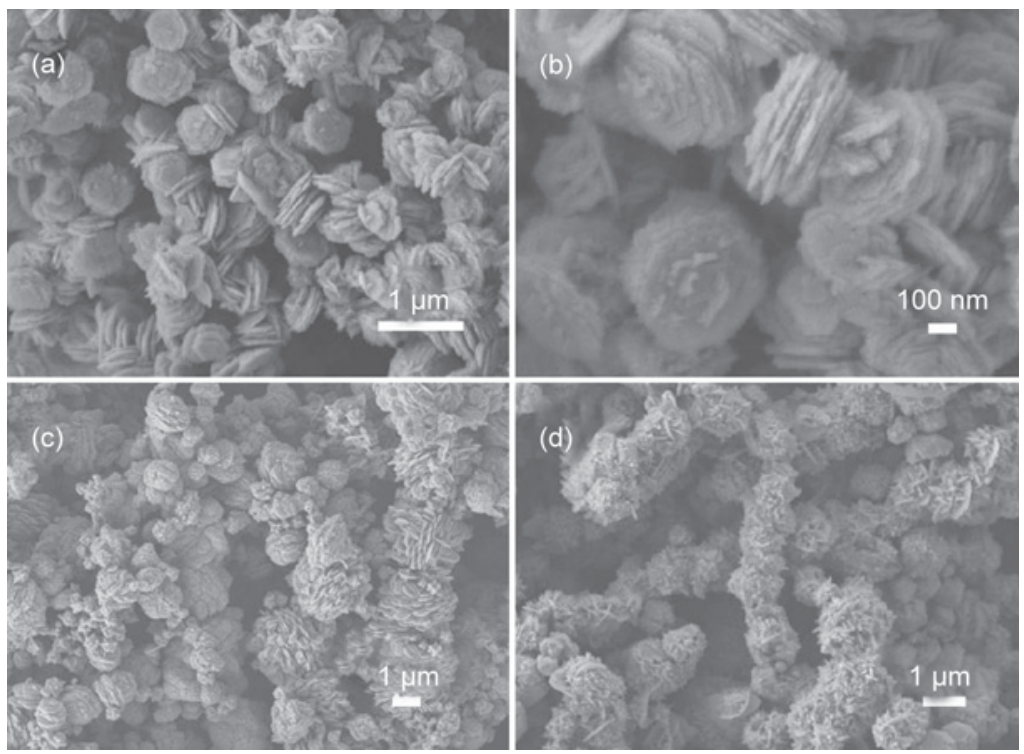

Figure 4 SEM images of $\mathrm{Ni}_{0.5} \mathrm{CO}_{0.5}$ synthesized in 1,2-propanediol at $170{ }^{\circ} \mathrm{C}$ with different concentrations of $\mathrm{NaOH}$ : (a) $[\mathrm{NaOH}]=1 \mathrm{~mol} / \mathrm{L}$; (b) $[\mathrm{NaOH}]=1 \mathrm{~mol} / \mathrm{L}$; (c) $[\mathrm{NaOH}]=2 \mathrm{~mol} / \mathrm{L}$; (d) $[\mathrm{NaOH}]=6 \mathrm{~mol} / \mathrm{L}$ acetate, acetylacetonate, and sulfate salts.

It was found that uniform $\mathrm{Ni}_{x} \mathrm{Co}_{1-x}$ particles were obtained in each case and the morphology of the particles is almost independent of the anion.

When the concentration of $\mathrm{NaOH}$ was increased from $0.1 \mathrm{~mol} / \mathrm{L}$ to $1.0 \mathrm{~mol} / \mathrm{L}$, the morphology of products changed from spherical particles to multilayer stacked structures (Figs. 4(a), (b)). Each stacked structure is composed of alloy plates with thicknesses of several tens of nanometers. XRD shows that these alloy plates are still an fcc phase (see Fig. S-5 in the ESM). With a further increase in the concentration of $\mathrm{NaOH}$ to $2 \mathrm{~mol} / \mathrm{L}$ or $6 \mathrm{~mol} / \mathrm{L}$, the products gradually turn into "alloy flowers" composed of many small alloy plates (Figs. 4(c), (d)). Apparently, $\mathrm{NaOH}$ concentration is the main factor affecting the morphology of the alloy particles.

\subsection{Structures and morphology of $\mathrm{Ni}-\mathrm{Co}$ microparticles synthesized in the presence of a magnetic field}

A $0.08 \mathrm{~T}$ external magnetic field was applied during the synthesis in order to study the effect of an external magnetic field on the assembly of the magnetic alloy products. When the $\mathrm{NaOH}$ concentration was 0.1 $\mathrm{mol} / \mathrm{L}$, alloy microchains could be produced. Figure 5 shows SEM images of alloy particles prepared in the absence and in the presence of an external magnetic field. Nearly monodisperse alloy particles were formed without an external magnetic field (Fig. 5(a)), but long straight single chain-like structures were obtained in the presence of an external magnetic field (Fig. 5(b)). Obviously, the external magnetic field plays a key role in the formation of one-dimensional

\section{凪: Springer}




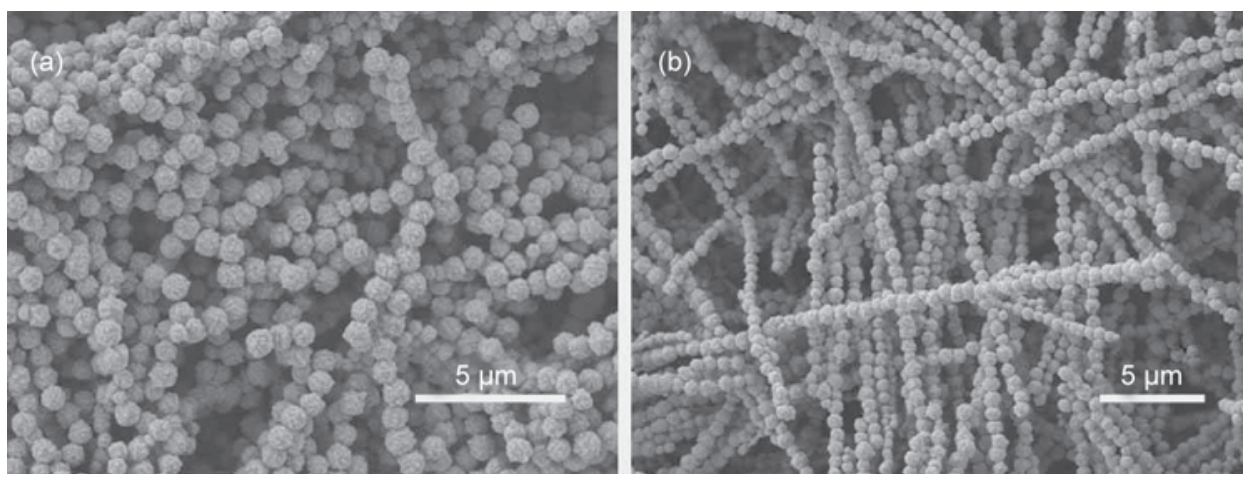

Figure 5 SEM images of samples prepared in 1,2-propanediol at $170{ }^{\circ} \mathrm{C}$ for $20 \mathrm{~h}$ : (a) SEM images of $\mathrm{Ni}-\mathrm{Co}$ particles prepared in the absence of a magnetic field; (b) SEM images of $\mathrm{Ni}-\mathrm{Co}$ particles prepared in the presence of a magnetic field. $[\mathrm{NaOH}]=0.1 \mathrm{~mol} / \mathrm{L}$

chainlike $\mathrm{Ni}_{x} \mathrm{Co}_{1-x}$ structures.

Similarly, one-dimensional assemblies of alloy microstructures can be obtained by increasing the $\mathrm{NaOH}$ concentration under a $0.08 \mathrm{~T}$ applied magnetic field. Figure 6 shows SEM images of the one-dimensional assemblies of alloy microstructures obtained with different $\mathrm{NaOH}$ concentrations. When the concentration of $\mathrm{NaOH}$ was $1 \mathrm{~mol} / \mathrm{L}$, the products were mainly composed of one-dimensional assemblies of multilayer stacked alloy plates (Figs. $6(\mathrm{a}),(\mathrm{b}))$. Figure $6(\mathrm{~b})$ shows that the nanoplates in these multilayer stacked structures are disordered under the applied field, and the nanoplates do not
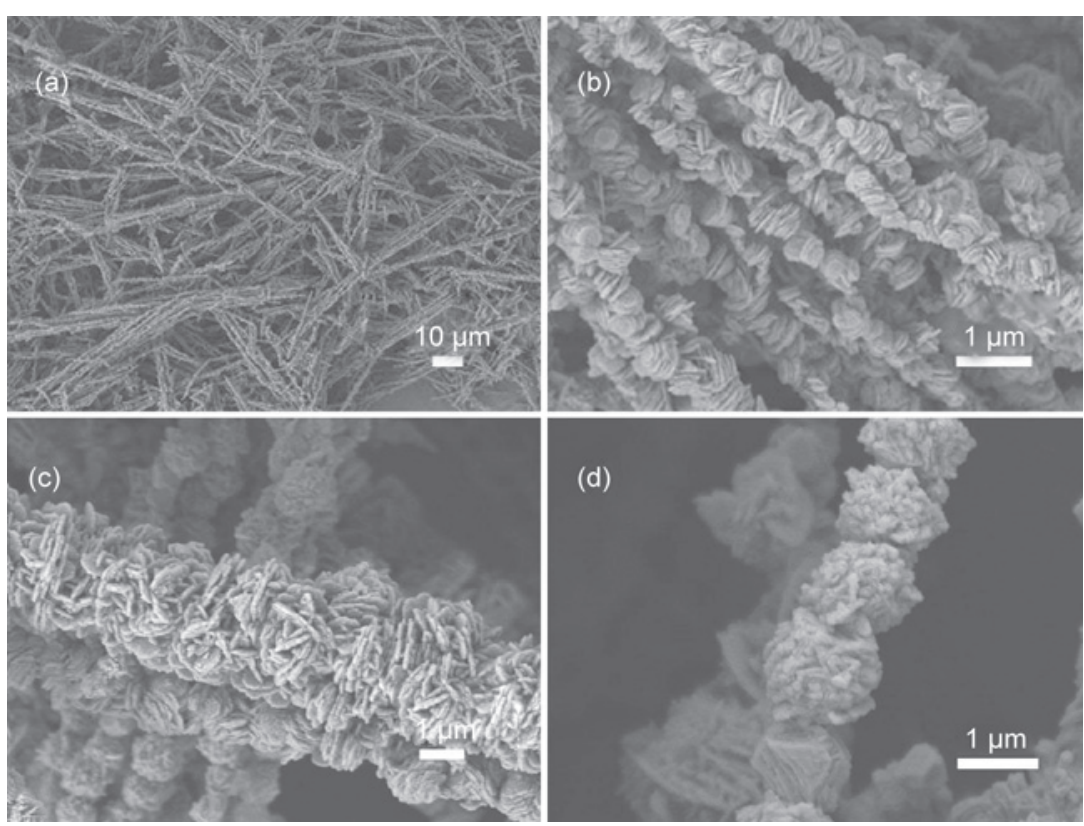

Figure 6 (a), (b) SEM images with different magnifications of the samples prepared in 1,2-propanediol when the concentration of $\mathrm{NaOH}$ is $1 \mathrm{~mol} / \mathrm{L}$. SEM images of the samples when the concentrations of $\mathrm{NaOH}$ are $2 \mathrm{~mol} / \mathrm{L}$ (c) and $6 \mathrm{~mol} / \mathrm{L}$ (d), respectively. A $0.08 \mathrm{~T}$ applied magnetic field was applied in each case show an ordered onedimensional arrangement along the magnetization direction, since this would result in a higher-level parallel stacked structure composed of multilayer stacked alloy plates. This seems to indicate that the one-dimensional arrangement of these alloy plates can be attributed to in situ growth of alloy products, rather than rearrangement of previously formed alloy plates, and that their growth direction was not affected by such a weak applied field. At higher $\mathrm{NaOH}$ concentrations $(2 \mathrm{~mol} / \mathrm{L}$ and $6 \mathrm{~mol} / \mathrm{L})$, onedimensional assemblies were still obtained. However, these one-dimensional assemblies were composed of disordered smaller alloy plates (Figs. 6(c), (d)), rather than the stacked alloy plates synthesized with $1 \mathrm{~mol} /$ $\mathrm{L} \mathrm{NaOH}$ solution.

Based on the above experiments, a possible mechanism for the formation of the one-dimensional assemblies of $\mathrm{Ni}_{x} \mathrm{Co}_{1-x}$ alloy products can be proposed. Initially, a large number of $\mathrm{Ni}_{x} \mathrm{Co}_{1-x}$ nuclei precipitate out of polyol solution at high temperature. These are then magnetized under the external magnetic field. Dipole-dipole interaction will tend to make them form ordered arrays, but as the nuclei are so small the dipole interactions are not strong enough to overcome molecular resistance of rigid molecules, such as HMT, and there are some gaps between neighboring nuclei. With prolonged reaction times, these nuclei gradually grow in size. In the case of one-dimensional assembly of alloy particles, the gaps between neighbouring nuclei will be filled by growing alloy nuclei and the larger alloy particles will be affected more markedly by the external magnetic field. Finally, neighboring 
particles will come into contact and link together to form chainlike structures under the influence of the magnetic field. The resulting chains keep parallel with the external magnetic force lines and form straight chain-like structures. The mechanism of formation of one-dimensional assemblies of alloy plates is similar to that for the formation of alloy particle chains. Ordered alloy nuclei with gaps between them grow by an in situ process along particular growth directions to form alloy plates. Larger plates are more significantly affected by the external magnetic field, leading to the formation of one-dimensional assemblies with different orientations of alloy plates. In order to further understand the magnetic fieldinduced assembly process, the assembly of alloy particles under different conditions with a constant magnetic field was studied.

First of all, the effect of varying precursor concentration on the assembly process was studied. In the experiments, the external magnetic field and the concentration of $\mathrm{NaOH}$ were kept constant, and the molar ratio of HMT to metal ions was kept at 1.5:1. Figure 7 shows that the average size of the particles decreased slightly and the length of the chains decreased significantly with increasing precursor concentration. For example, when the precursor concentration was $0.02 \mathrm{~mol} / \mathrm{L}$, the average length of alloy chains was about $150 \mu \mathrm{m}$ (Fig. 7(a)). When the precursor concentration was $0.03 \mathrm{~mol} /$ $\mathrm{L}$, most chains only had a length in the range $10 \mu \mathrm{m}$ to $20 \mu \mathrm{m}$ (Fig. 7(b)). When the concentration was $0.04 \mathrm{~mol} / \mathrm{L}$, the average chain length decreased further to about $6 \mu \mathrm{m}$ (Fig. 7(c)). When the concentration reached 0.06 $\mathrm{mol} / \mathrm{L}$, the influence of the external magnetic field nearly disappeared and the shape of the products was almost the same as that of products obtained in the absence of an external magnetic field (Fig. 7(d)). The marked effect of precursor concentration on the length of the alloy chain is consistent with the formation mechanism of the onedimensional alloy microstructures proposed above, showing the existence of some molecular resistance. The precursor concentration only has a slight effect on the particle size. It was found that the average particle sizes for increasing precursor concentrations of $0.02 \mathrm{~mol} / \mathrm{L}, 0.03 \mathrm{~mol} / \mathrm{L}, 0.04 \mathrm{~mol} / \mathrm{L}$, and $0.06 \mathrm{~mol} / \mathrm{L}$, showed a gradual decrease with the values being $900 \mathrm{~nm}, 800 \mathrm{~nm}, 750 \mathrm{~nm}$, and $600 \mathrm{~nm}$, respectively.

Interestingly, the length of the particle chains depends on the precursor concentration. On the one hand, with increasing HMT concentration (the precursor:HMT ratio being fixed), some complicated elevated temperature chemical reactions in such a polyol system will lead to the generation of new organic molecules, as suggested by the presence of a large amount of organic flocculation at high HMT concentrations. These organic products might inhibit the mutual attraction between particles and promote the formation of separate and dispersed particles. On the other hand, as higher reaction rates occur at high concentration, many nuclei will appear at the beginning of the reaction and then grow to form a large number of particles. Under an external magnetic field, each particle can be regarded as a small magnet after it is magnetized, and these small magnets will themselves generate
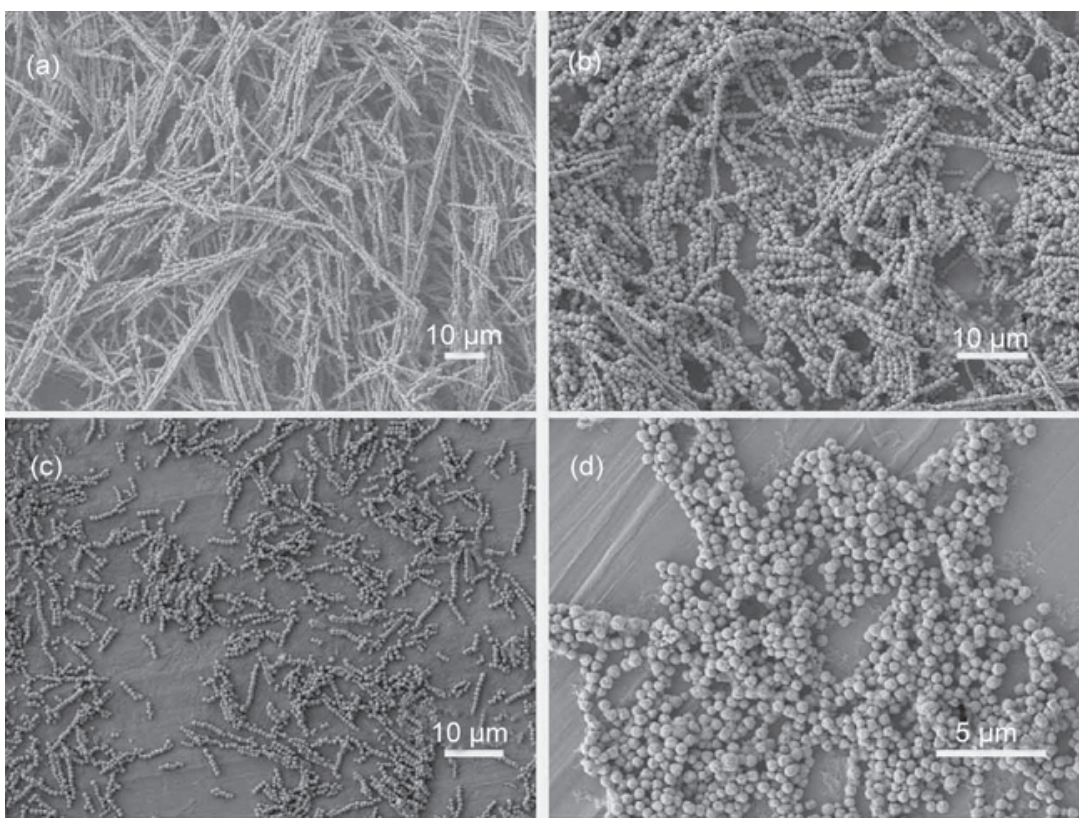

Figure 7 SEM images of $\mathrm{Ni}_{0.5} \mathrm{CO}_{0.5}$ chains synthesized using different precursor concentrations in a constant external magnetic field. The precursor concentrations for (a), (b), (c), (d) were $0.02 \mathrm{~mol} / \mathrm{L}, 0.03 \mathrm{~mol} / \mathrm{L}, 0.04 \mathrm{~mol} / \mathrm{L}$, and $0.06 \mathrm{~mol} / \mathrm{L}$, respectively 


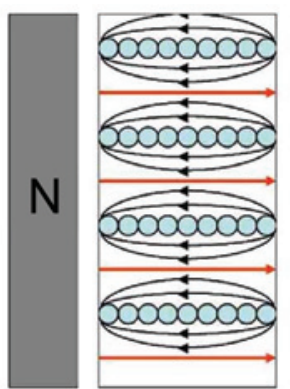

(a)

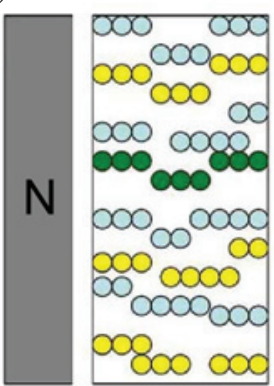

(e)

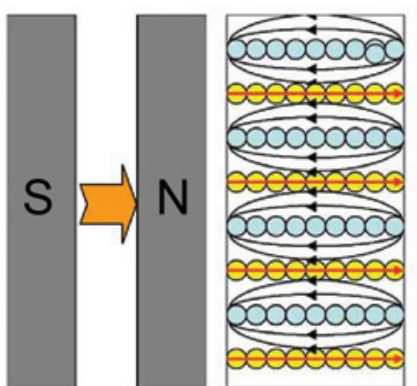

(b)

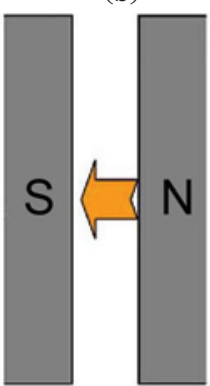

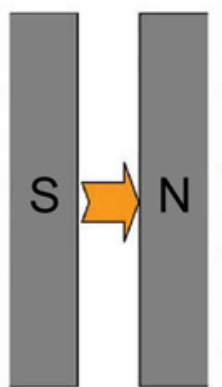
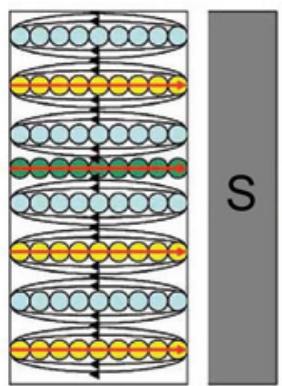

Scheme 1 Schematic illustration of the formation process of chain-like particles in the presence of an external magnetic field. If it is assumed that chains of the same length are formed at different precursor concentrations, then more chains will be formed at higher precursor concentrations. $\mathrm{N}$ and $S$ represent the North Pole and South Pole, respectively, of two external permanent magnets. Red and black lines represent external field magnetic force lines and interior magnetic force lines generated by the alloy chains, respectively: (a) magnetic states at low precursor concentration, where blue dots represent $\mathrm{Ni}_{0.5} \mathrm{Co}_{0.5}$ particles; (b) magnetic states when the precursor concentration is twice that in (a), where yellow dots represent more newly formed chain-like particles with increased precursor concentration; (c) the green chain shows that a single chain will be affected by more chains in the case of high precursor concentration and is disturbed by many local weak magnetic fields generated by short chains; (d), (e) with increasing precursor concentration, more short chains will be formed as the magnetic intensity becomes weaker

magnetic force lines which affect the magnetization and arrays of other particles. Thus, at high precursor concentrations, each particle will be affected by more weak local magnetic fields generated by other particles than is the case for low concentrations, the magnetization degree of each particle will thus decrease, and the attraction between adjacent particles becomes weaker, so that the stability of chains becomes lower, and finally dispersed particles and shorter chains are formed. Scheme 1 shows the possible formation mechanism of short chains under the synergistic effect of the external magnetic field and local magnetic fields. It needs to be stated that the proposal that a combination of the above two factors induces the formation of short chains is based on experiment, because it was found that the length of the alloy chain was not changed so significantly by merely changing one of the two factors, i.e., keeping the HMT concentration constant and varying the precursor concentration or vice versa.

Alloy chains with different $\mathrm{Ni}-\mathrm{Co}$ composition have also been studied. In this case, $\mathrm{NaOH}$ concentration and total precursor concentration were kept constant. It was found that chains with nearly the same structure were obtained, but the particle sizes and the lengths of the chains were different. Figure 8 shows that the average sizes of $\mathrm{Ni}_{0.2} \mathrm{Co}_{0.8}$, $\mathrm{Ni}_{0.5} \mathrm{Co}_{0.5}$ and $\mathrm{Ni}_{0.8} \mathrm{Co}_{0.2}$ particles are about $800 \mathrm{~nm}$, $900 \mathrm{~nm}$, and $500 \mathrm{~nm}$, respectively, and the average lengths of the chains are about $80 \mu \mathrm{m}, 150 \mu \mathrm{m}$, and $250 \mu \mathrm{m}$, respectively. Figure 8(c) shows super long and straight $\mathrm{Ni}_{0.8} \mathrm{Co}_{0.2}$ alloy chains, with some chain lengths reaching hundreds of micrometers. Figure 8(d) shows a higher magnification SEM image of the $\mathrm{Ni}_{0.8} \mathrm{Co}_{0.2}$ alloy chains, which shows closer contacts between adjacent particles and more ordered alignment of particles than those found in the $\mathrm{Ni}_{0.5} \mathrm{Co}_{0.5}$ and $\mathrm{Ni}_{0.2} \mathrm{Co}_{0.8}$ particles. This suggests that 

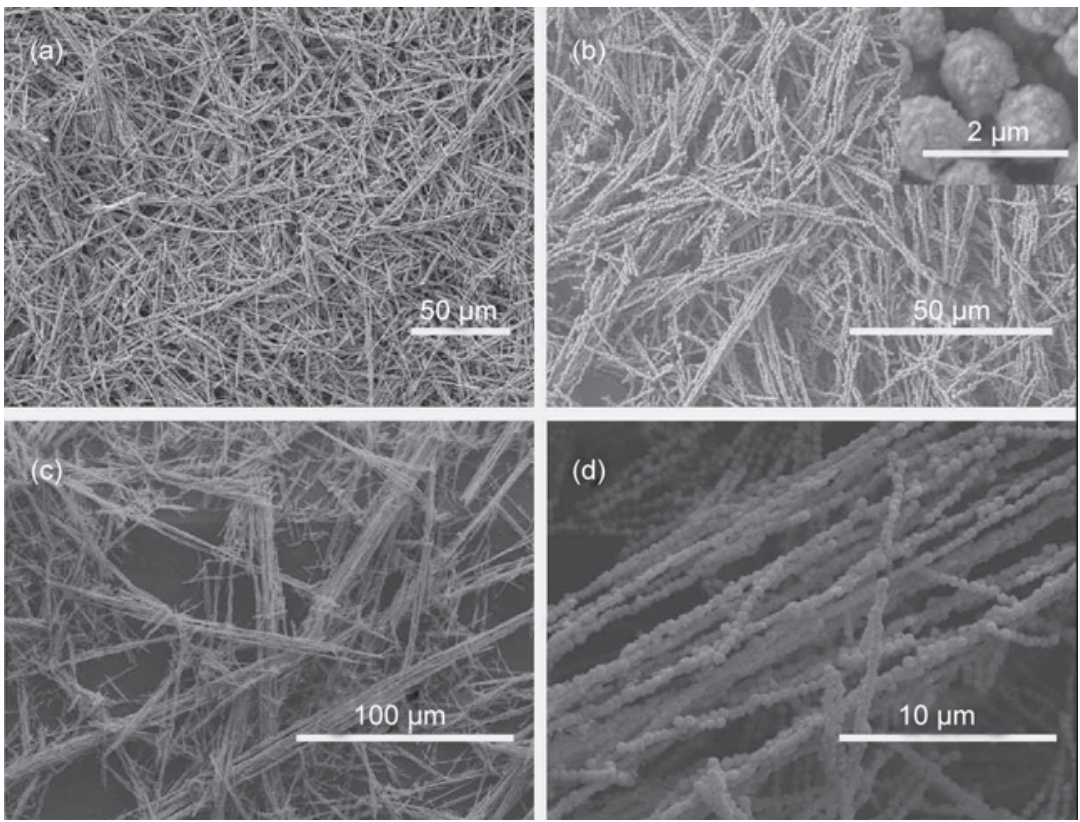

Figure 8 (a), (b), (c) Low-magnification SEM images of long chain-like $\mathrm{Ni}_{0.2} \mathrm{CO}_{0.8}, \mathrm{Ni}_{0.5} \mathrm{CO}_{0.5}$ $\mathrm{Ni}_{0.8} \mathrm{C}_{0.2}$ particles formed in the presence of an external magnetic field. The insert in (b) is a high-magnification image of $\mathrm{Ni}_{0.5} \mathrm{CO}_{0.5}$ particles. (d) Higher magnification SEM image of chain-like $\mathrm{Ni}_{0.8} \mathrm{CO}_{0.2}$ particles. The precursor concentration was kept constant $(0.02 \mathrm{~mol} / \mathrm{L})$ with hydroxide ions disturbs the interaction of the surfactants with metal ions, because smaller alloy particles can be obtained at higher reaction temperatures in such a polyol process with addition of surfactant but without sodium hydroxide (see Fig. S-6 in the ESM).

\section{Conclusions}

In summary, one-dimensional magnetic $\mathrm{Ni}-\mathrm{Co}$ alloy microwires with different microstructures and building blocks with a variety of morphologies including spherical particles, multilayer stacked alloy plates, and alloy flowers, can be synthesized by an external magnetic field-assisted solvothermal reaction of a mixture of cobalt(II) chloride and since Ni has a larger susceptibility, with increasing $\mathrm{Ni}$ content in the alloy, the particles will be affected more markedly by an external magnetic field.

Finally, it was found that the influence of surfactant on the particle size and distribution was not significant. Addition of PVP led to a slight decrease in the size of particles and poorer dispersivity of the particles, because PVP molecules were usually coated on the surface of particles and were difficult to wash away completely (Fig. 9(a)). Cetyltrimethylammonium bromide (CTAB) and sodium oleate (SOA) also had no obvious influence on the size and morphology of the alloy particles (Figs. 9(b), (c)). The reason might be that the preferential complexation of $\mathrm{Ni}(\mathrm{II})$ and $\mathrm{Co}(\mathrm{II})$
nickel(II) chloride in 1,2-propanediol with different $\mathrm{NaOH}$ concentrations. Alloy chains with uniform diameters in the range $500 \mathrm{~nm}$ to $1.3 \mu \mathrm{m}$ and lengths ranging from several micrometers to hundreds of micrometers can be selectively synthesized by tuning the precursor concentration and $\mathrm{Ni} / \mathrm{Co}$ ratio. A possible mechanism for the formation of onedimensional assemblies of magnetic particles and the dependence of the length of the alloy chains on precursor concentration in the presence of a weak external magnetic field has been proposed. Further studies of the magnetic properties and potential applications of these alloys as anode materials in solid oxide fuel cells are underway in our laboratory.
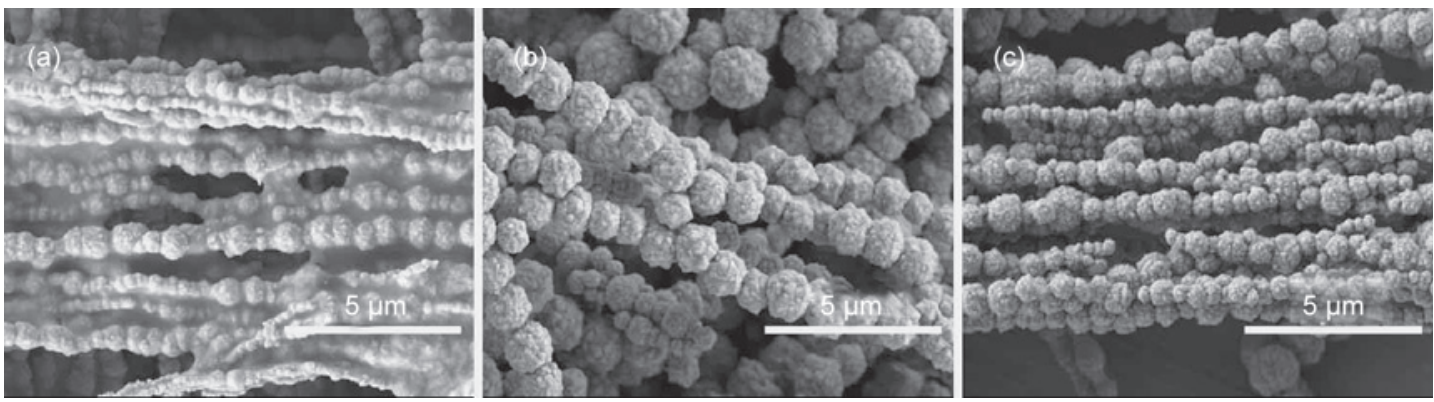

Figure 9 SEM images of the $\mathrm{Ni}_{0.5} \mathrm{CO}_{0.5}$ products synthesized in 1,2-propanediol with addition of different surfactants under a constant magnetic field: (a) PVP; (b) CTAB; (c) SOA. [NaOH] $=0.1 \mathrm{~mol} / \mathrm{L}, 170^{\circ} \mathrm{C}, 20 \mathrm{~h}$

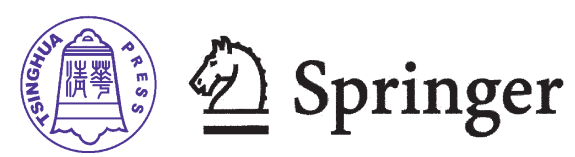




\section{Acknowledgments}

This work was supported by the National Natural Science Foundation of China (NSFC) (Grants Nos. 50732006, 20621061, and 20671085), Anhui Development Fund for Talented Personnel (2005CB623601) and Anhui Education Committee (2006Z027, ZD2007004-1), the Specialized Research Fund for the Doctoral Program (SRFDP) of Higher Education State Education Ministry, and the PartnerGroup of the Chinese Academy of Sciences-the Max Planck Society.

Electronic Supplementary Material: EDX spectra, SEM images, TEM images of the product and intermediate products are available in the online version of this article at http://dx.doi.org/10.1007/ s12274-008-8031-6 and are accessible free of charge.

\section{References}

[1] Link, S.; El-Sayed, M. A. Optical properties and ultrafast dynamics of metallic nanocrystals. Annu. Rev. Phys. Chem. 2003, 54, 331-366.

[2] Lu, A. -H.; Salabas, E. L.; Schüth, F. Magnetic nanoparticles: Synthesis, protection, functionalization, and application. Angew. Chem. Int. Ed. 2007, 46, 1222-1244.

[3] Braun, E.; Eichen, Y.; Sivan, U.; Ben-Yoseph, G. DNAtemplated assembly and electrode attachment of a conducting silver wire. Nature 1998, 391, 775-778.

[4] Narayanan, R.; El-Sayed, M. A. Catalysis with transition metal nanoparticles in colloidal solution: Nanoparticle shape dependence and stability. J. Phys. Chem. B 2005, 109, 12663-12676.

[5] Toshima, N.; Yonezawa, T. Bimetallic nanoparticles—novel materials for chemical and physical applications. New J. Chem. 1998, 22, 1179-1201.

[6] Luo, X. L.; Morrin, A.; Killard, A. J.; Smyth, M. R. Application of nanoparticles in electrochemical sensors and biosensors. Electroanalysis 2006, 18, 319-326.

[7] Gu, C.; Lian, J.; Jiang, Z. High strength nanocrystalline $\mathrm{Ni}-\mathrm{Co}$ alloy with enhanced tensile ductility. Adv. Eng. Mater. 2006, 8, 252-256.

[8] Wang, L.; Gao, Y.; Xue, Q.; Liu, H.; Xu, T. Microstructure and tribological properties of electrodeposited $\mathrm{Ni}-\mathrm{Co}$ alloy deposits. Appl. Surf. Sci. 2005, 242, 326-332.
[9] Kritzer, P.; Boukis, N.; Dinjus, E. Review of the corrosion of nickel-based alloys and stainless steels in strongly oxidizing pressurized high-temperature solutions at subcritical and supercritical temperatures. Corrosion 2000, 56, 1093-1104.

[10] Singh, V. B.; Singh, V. N. Electrodeposition of nickelcobalt alloys from acetate bath. Plat. Surf. Finish. 1976, 63, 34-36.

[11] Hibbard, G. D.; Aust, K. T.; Erb, U. Thermal stability of electrodeposited nanocrystalline $\mathrm{Ni}-\mathrm{Co}$ alloys. Mat. Sci. Eng. A 2006, 433, 195-202.

[12] Domínguez-Crespo, M. A.; Plata-Torres, M.; TorresHuerta, A. M.; Arce-Estrada, E. M.; Hallen-López, J. M. Kinetic study of hydrogen evolution reaction on $\mathrm{Ni}_{30} \mathrm{Mo}_{70}$, $\mathrm{CO}_{30} \mathrm{Mo}_{70}, \mathrm{CO}_{30} \mathrm{Ni}_{70}$ and $\mathrm{CO}_{10} \mathrm{Ni}_{20} \mathrm{Mo}_{70}$ alloy electrodes. Mater. Charact. 2005, 55, 83-91.

[13] Chi, B.; Li, J.; Yang, X.; Gong, Y.; Wang, N. Deposition of $\mathrm{Ni}-\mathrm{Co}$ by cyclic voltammetry method and its electrocatalytic properties for oxygen evolution reaction. Int. J. Hydrogen. Energ. 2005, 30, 29-34.

[14] Mercier, D.; Lévy, J. -C. S.; Viau, G.; Fiévet-Vincent, F.; Fiévet, F. Magnetic resonance in spherical Co-Ni and FeCo-Ni particles. Phys. Rev. B 2000, 62, 532-544.

[15] Masoeroa, A.; Mortenb, B.; Olcesec, G. L.; Prudenziatib, M.; Tangod, F.; Vinai, F. Magnetic properties of $\mathrm{Ni}-\mathrm{Co}$ thick-film magnetoresistors. Thin Solid Films 1999, 350, 214-218.

[16] Atkinson, A.; Barnett, S.; Gorte, R. J.; Irvine, J. T. S.; McEvoy, A. J.; Mogensen, M.; Singhal, S. C.; Vohs, J. Advanced anodes for high-temperature fuel cells. Nat. Mater. 2004, 3, 17-27.

[17] Zhang, L.; Bain, J. A.; Zhu, J. -G.; Abelmann, L.; Onoue, T. Dynamic domain motion of thermal-magnetically formed marks on CoNi/Pt multilayers. J. Appl. Phys. 2006, 100, 053901.

[18] Onoue, T.; Siekman, M. H.; Abelmann, L. Heat-assisted magnetic probe recording on a CoNi/Pt multilayered film. J. Magn. Magn. Mater. 2005, 287, 501-506.

[19] Golodnitsky, D.; Rosenberg, Y.; Ulus, A. The role of anion additives in the electrodeposition of nickel-cobalt alloys from sulfamate electrolyte. Electrochim. Acta 2002, 47, 2707-2714.

[20] Armyanov, S. Crystallographic structure and magnetic properties of electrodeposited cobalt and cobalt alloys. Electrochim. Acta 2000, 45, 3323-3335.

[21] Aymard, L.; Dumont, B.; Viau, G. Production of Co-Ni 
alloys by mechanical-alloying. J. Alloy. Compd. 1996, 242, 108-113.

[22] Uzawa, M.; Inoue, A.; Masumoto, T. Morphology and properties of ultrafine $\mathrm{Ni}-\mathrm{Fe}$ and $\mathrm{Ni}-\mathrm{Co}$ alloy particles prepared by leaching amorphous $\mathrm{Al}-\mathrm{Ni}-\mathrm{Fe}-\mathrm{Ce}$ and $\mathrm{Al}-\mathrm{Ni}-$ Co-Ce alloys. Mater. Sci. Eng. A 1994, 182, 1179-1183.

[23] Sangregorio, C.; Fernández, C. de J.; Battaglin, G.; De, G.; Gatteschi, D.; Mattei, G.; Mazzoldi, P. Magnetic properties of Co-Ni alloy nanoparticles prepared by the sol-gel technique. J. Magn. Magn. Mater. 2004, 272, E1251-E1252.

[24] Syukri; Ban, T.; Ohya, Y.; Takahashi, Y. A simple synthesis of metallic $\mathrm{Ni}$ and $\mathrm{Ni}-\mathrm{Co}$ alloy fine powders from a mixed-metal acetate precursor. Mater. Chem. Phys. 2003, 78, 645-649.

[25] Ung, D.; Viau, G.; Ricolleau, C.; Warmont, F.; Gredin, P.; Fiévet, F. CoNi nanowires synthesized by heterogeneous nucleation in liquid polyol. Adv. Mater. 2005, 17, 338-344.

[26] Ung, D.; Soumare, Y.; Chakroune, N.; Viau, G.; Vaulay, M. -J.; Richard, V. Growth of magnetic nanowires and nanodumbbells in liquid polyol. Chem. Mater. 2007, 19, 2084-2094.

[27] Li, Y. D.; Li, L. Q.; Liao, H. W.; Wang, H. R. Preparation of pure nickel, cobalt, nickel-cobalt and nickel-copper alloys by hydrothermal reduction. J. Mater. Chem. 1999, 9, 2675-2677.

[28] Zhu, L. -P.; Xiao, H. -M.; Fu, S. -Y. Surfactant-assisted synthesis and characterization of novel chain-like CoNi alloy assemblies. Eur. J. Inorg. Chem. 2007, 3947-3951.

[29] Qin, D. H.; Wang, C. W.; Sun, Q. Y.; Li, H. L. The effects of annealing on the structure and magnetic properties of CoNi patterned nanowire arrays. Appl. Phys. A 2002, 74, 761-765.

[30] Zhang, D. -E.; Ni, X. -M.; Zhang, X. -J.; Zheng, H. -G. Synthesis and characterization of $\mathrm{Ni}-\mathrm{Co}$ needle-like alloys in water-in-oil microemulsion. J. Magn. Magn. Mater. 2006, 302, 290-293.

[31] Niu, H. L.; Chen, Q. W.; Ning, M.; Jia, Y. S.; Wang, X. J. Synthesis and one-dimensional self-assembly of acicular nickel nanocrystallites under magnetic fields. J. Phys. Chem. B 2004, 108, 3996-3999.

[32] Sun, L.; Chen, Q.; Tang, Y.; Xiong, Y. Formation of onedimensional nickel wires by chemical reduction of nickel ions under magnetic fields. Chem. Commun. 2007, 2844-2846.

[33] Wang, J.; Chen, Q. W.; Zeng, C.; Hou, B. Y. Magnetic- field-induced growth of single-crystalline $\mathrm{Fe}_{3} \mathrm{O}_{4}$ nanowires. Adv. Mater. 2004, 16, 137-140.

[34] He, Z.; Yu, S. -H.; Zhou, X.; Li, X.; Qu, J. Magneticfield-induced phase-selective synthesis of ferrosulfide microrods by a hydrothermal process: Microstructure control and magnetic properties. Adv. Funct. Mater. 2006, 16, 1105-1111.

[35] Zeng, J.; Huang, J.; Lu, W.; Wang, X.; Wang, B.; Zhang, S.; Hou, J. Necklace-like noble-metal hollow nanoparticle chains: Synthesis and tunable optical properties. Adv. Mater. 2007, 19, 2172-2176.

[36] Sun, J.; Zhang, Y.; Chen, Z.; Zhou, J.; Gu, N. Fibrous aggregation of magnetite nanoparticles induced by a time-varied magnetic field. Angew. Chem. Int. Ed. 2007, 46, 4767-4770.

[37] Commeinhes, X.; Davidson, P.; Bourgaux, C.; Livage, J. Orientation of liquid-crystalline suspensions of vanadium pentoxide ribbons by a magnetic field. Adv. Mater. 1997, 9, 900-903.

[38] Kimura, T.; Sato, Y.; Kimura, F.; Iwasaka, M.; Ueno, S. Micropatterning of cells using modulated magnetic fields. Langmuir 2005, 21, 830-832.

[39] Garmestani, H.; Al-Haik, M. S.; Dahmen, K.; Tannenbaum, R.; Li, D.; Sablin, S. S.; Hussaini, M. Y. Polymer-mediated alignment of carbon nanotubes under high magnetic fields. Adv. Mater. 2003, 15, 1918-1921.

[40] Kimura, T.; Yamato, M.; Nara., A. Particle trapping and undulation of a liquid surface using a microscopically modulated magnetic field. Langmuir 2004, 20, 572-574.

[41] Hu, M. J.; Lu, Y.; Zhang, S.; Guo, S. R.; Lin, B.; Zhang, M.; $\mathrm{Yu}, \mathrm{S}$. H. High yield synthesis of bracelet-like hydrophilic $\mathrm{Ni-Co}$ magnetic alloy flux-closure nanorings. J. Am. Chem. Soc. 2008, 130, 11606-11607.

[42] Mattei, G.; de Julian Fernández, C.; Mazzoldi, P.; Sada, C. Synthesis, structure, and magnetic properties of $\mathrm{Co}, \mathrm{Ni}$, and $\mathrm{Co}-\mathrm{Ni}$ alloy nanocluster-doped $\mathrm{SiO}_{2}$ films by sol-gel processing. Chem. Mater. 2002, 14, 3440-3447.

[43] Henglein, A.; Giersig, M. Radiolytic formation of colloidal tin and tin-gold particles in aqueous solution. J. Phys. Chem. 1994, 98, 6931-6935.

[44] Jiang, H.; Moon, K. -S.; Wong, C. P. Synthesis of Ag-Cu alloy nanoparticles for lead-free interconnect materials. Proceedings of the 2005 IEEE/CPMT 10th International Symposium on Advanced Packaging Materials: Processes, Properties and Interfaces, Beckman Center, Irvine, CA, March, 2005(CD-ROM only); ISBN 0-7803-9085-7.

\section{凰商: Springer}

